\title{
An Unusual Maxillary Sinus Foreign Body and Its Endoscopic Assisted Removal
}

\author{
R. V. Nataraj, Mohan Jagade, Reshma Chavan, Rajesh Kar, Madhavi Pandare, \\ Kartik Parelkar, Arpita Singhal, Kiran Kulsange \\ Department of Ear, Nose \& Throat and Head \& Neck Surgery, Grant Government Medical College, Mumbai, \\ India \\ Email: nataraj.rv@gmail.com
}

Received 23 December 2014; accepted 18 January 2015; published 22 January 2015

Copyright (C) 2015 by authors and Scientific Research Publishing Inc.

This work is licensed under the Creative Commons Attribution International License (CC BY).

http://creativecommons.org/licenses/by/4.0/

(c) (i) Open Access

\begin{abstract}
Foreign bodies in maxillary sinuses are uncommon. But the incidence is on a rise. Herewith we present a case of foreign bodies (glass pieces) in left maxillary sinus and bilateral nasolacrimal ducts, which is managed endoscopically.
\end{abstract}

\section{Keywords}

\section{Maxillary Sinus, Foreign Body, Endoscopic Approach}

\section{Introduction}

Foreign bodies are very frequently encountered entities in routine ENT practice, which warrant immediate removal. Most common types, which are brought to the surgeon's notice, involve the ear, nose and pharynx. The procedures for removal of most of such foreign bodies are fair and can be performed in the OPD, with help of local anesthesia.

Foreign bodies in paranasal sinuses are still an uncommon clinical condition and the procedures for removal are far more challenging. The most common causes of paranasal foreign bodies are iatrogenic (60\%) or accidental (25\%) [1] [2]. The iatrogenic causes include various dental, ophthalmic and otorhinolaryngologic procedures [1] [2]. History regarding any of the above mentioned procedures should raise the suspicion of a paranasal foreign body.

The maxillary sinus is most frequently involved (75\%), followed by the frontal sinus (18\%) [1] [2]. There have been cases of foreign body which have been introduced willingly into the maxillary sinus [3]. The foreign bodies can be of varying natures such as dental fillings, broken fragments of tooth and bones, pieces of glass, stones, gunshot pellets etc.

How to cite this paper: Nataraj, R.V., Jagade, M., Chavan, R., Kar, R., Pandare, M., Parelkar, K., Singhal, A. and Kulsange, K. (2015) An Unusual Maxillary Sinus Foreign Body and Its Endoscopic Assisted Removal. International Journal of Otolaryngology and Head \& Neck Surgery, 4, 38-43. http://dx.doi.org/10.4236/ijohns.2015.41007 
Removal of paranasal foreign body is always a challenge. But with advent of advanced diagnostic procedures and endoscopic assisted surgeries, such surgeries can be performed safely with relative ease.

Hereby we report a case of foreign bodies (glass particles) lodged in both nasolacrimal ducts and left maxillary sinus following an accident, with a barely visible scar over the nose.

\section{Case Report}

A healthy 25 years old male presented to ophthalmology OPD with complaints of watering of left eye. A CT DCG was advised and bilateral nasolacrimal ducts were found to be blocked with impacted foreign bodies, most probably pieces of glass. Past history revealed that, 3 months ago, the patient was involved in a road traffic accident in which his vehicle hit a tree. As a result of which, patient's face came in contact with the vehicle's windshield. This resulted in multiple abrasions and lacerations over his face. Though most wounds were superficial, a few lacerations, over left side of the nose and the ones just below the eyes were deep enough to warrant primary closure. The routine investigations including, non contrast CT scan brain, were found to be normal. The wounds were sutured and the patient was discharged.

As the patient also complained of recurrent headache, left nasal discharge and post nasal drip, the patient was referred to our OPD for evaluation and further management. Upon anterior rhinoscopic examination revealed mild septal deviation to right, hypertrophied inferior turbinates on both sides and purulent and foul-smelling discharge from left nostril but no foreign body or any other nasal pathology could be visualized. Left maxillary sinus tenderness could, also, be elicited. Oral cavity was examined for evidence of oroantral fistula but none could be found. A barely visible scar was seen over the face just below the left eye (Figure 1 and Figure 2).

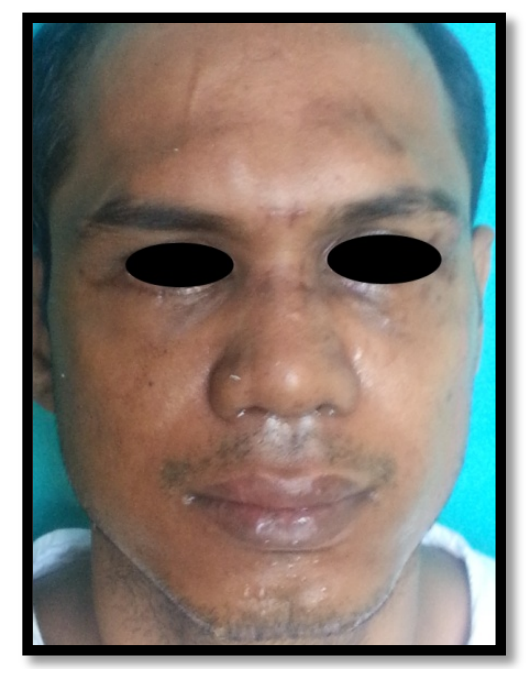

Figure 1. Patient with barely visible scar over his face.

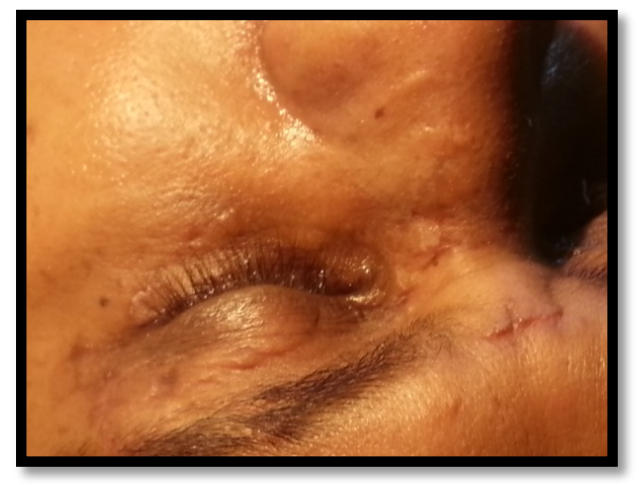

Figure 2. Close up of the scar. 
Syringing test revealed immediate and watery regurgitation from left eye. CT PNS (plain and contrast) revealed mucosal thickening of left maxillary sinus and multiple irregular foreign bodies, most probably glass particles, in left maxillary sinus, blocking the left ostium. There was no evidence of any fistula or sinuses (Figure 3 and Figure 4).

The patient was admitted and thoroughly investigated. Functional endoscopic sinus surgery and endoscopic dacrocystorhinostomy, in a single sitting, under general anesthesia were planned for the removal of the foreign bodies. Intra-operative findings revealed mucosa thickening in left maxillary sinus. Numerous small pieces of glass and three large irregular pieces of glass were found in the left maxillary sinus and ostia and one large piece of glass in each of the nasolacrimal duct (Figure 5 and Figure 6).

Bilateral nasal packing was done and patient was given antibiotic coverage for 48 hours post-operatively. and CT scan of paranasal sinuses showed no remnant foreign bodies. Patient was re-evaluated after 1 month and he

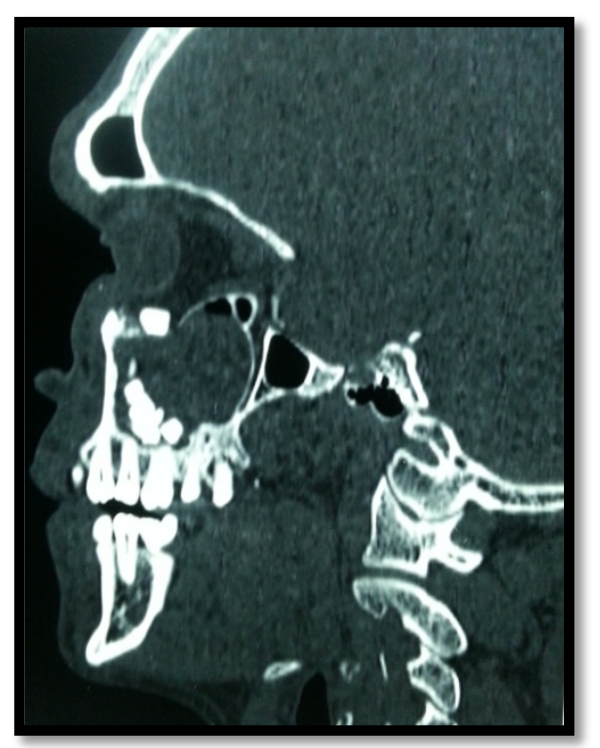

Figure 3. CT scan showing FB in left maxillary sinus and left NLD.

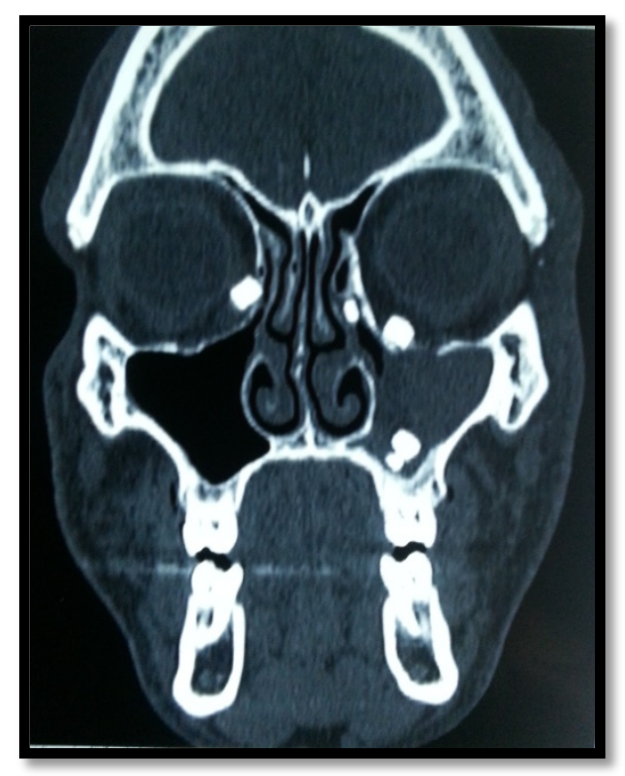

Figure 4. CT scan showing FB in bilateral NLD. 


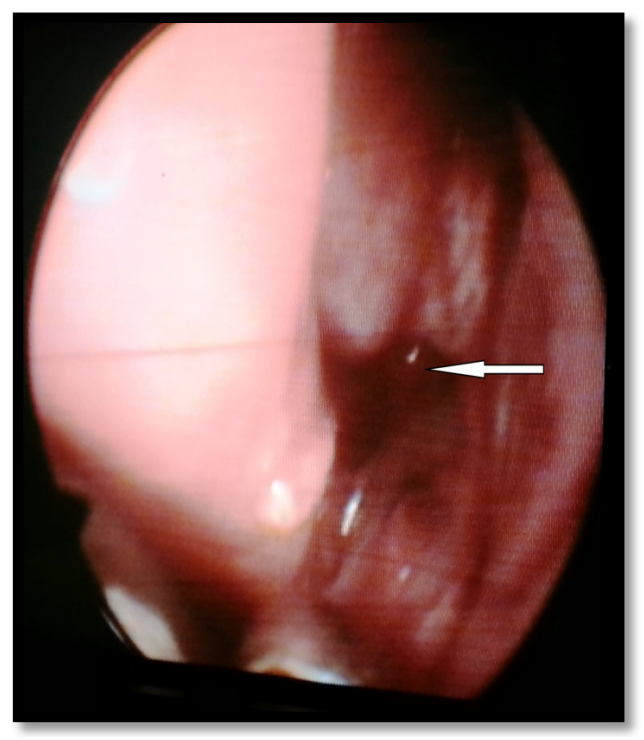

Figure 5. Endoscopic view of the FB.

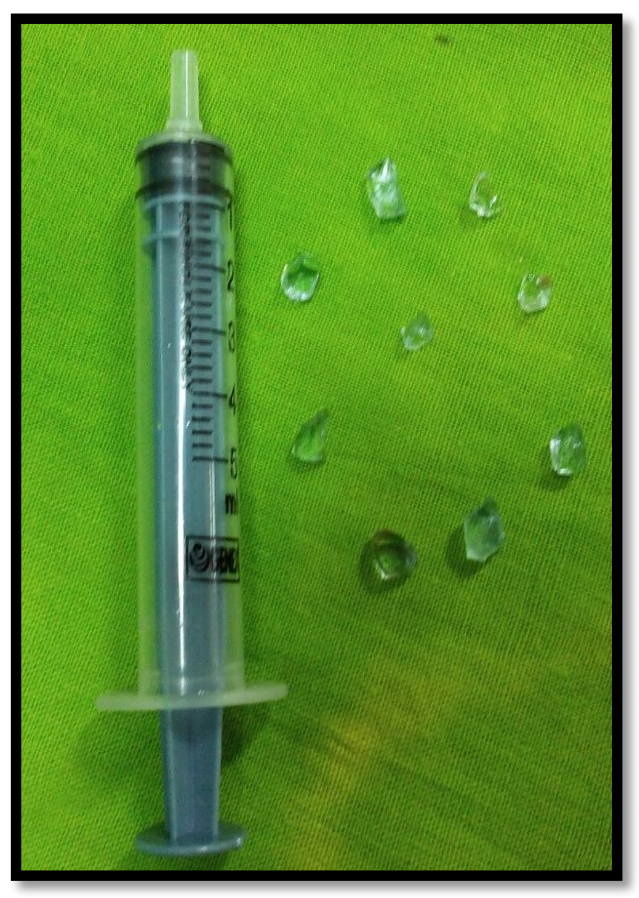

Figure 6. Glass pieces extracted.

underwent a diagnostic nasal endoscopy, which showed no evidence of residual foreign bodies. CT scan of paranasal sinuses was performed, which confirmed the endoscopic findings (Figure 7).

\section{Discussion}

Regardless of their origin, foreign bodies in maxillary sinus are a rare entity, especially in cases of unilateral sinusitis that is resistant to medical line of management. In such cases detailed history regarding long forgotten dental procedures and accidents needs to be elicited. Careful examination of the oral cavity is helpful to diagnose oroantral fistula. But absence of any fistula doesn't necessarily rules out foreign bodies as, more often than not, fistula heals leaving no evidence behind. The exact mechanism of how foreign body causes sinusitis is not 


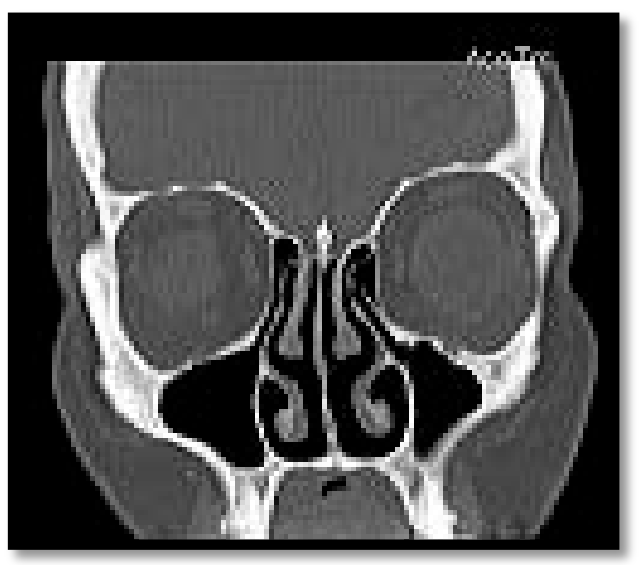

Figure 7. Post-operative CT scan.

known. However it has been postulated that foreign body causes chronic physical irritation of the mucosa leading to impaired cilliary movements and secondary infections. Foreign bodies can also obstruct the ostium leading to improper drainage. So removal of all the foreign bodies is necessary, even if they do not cause any symptoms [4].

Pre-operative CT scan is necessary for numerous reasons, chief amongst them being diagnostic. It not only shows the exact site, size and number of the foreign bodies but also detects the presence of any fistula. Site and size of the foreign bodies helps us in deciding between endoscopic approach and Caldwell-Luc procedure or combination of both. The most common procedure used is the endoscopic approach with a wide endonasal meatotomy. The advantages of functional endoscopic sinus surgery noted in literature include its less invasiveness, ability to fully visualize the antrum, a short recovery time and little or no risk of injury to the infraorbital nerve [5]-[8]. The potential problem of altered facial growth in children associated with the Caldwell-Luc operation is absent with this technique [9]. But in cases where the foreign body is too large or endoscopic approach fails, the surgery should be converted to an external approach using Caldwell-Luc procedure as it allows a much better visualization of the antrum. In recent literature a combination of Caldwell-Luc and endoscopic approach has been described as the gold standard procedure for treating various diseases of the maxillary sinus, including foreign body removal [5].

This case is unique and interesting for two reasons; first of all coexisting of both maxillary and nasolacrimal duct foreign bodies giving rise to symptoms of both chronic dacrocystitis and chronic sinusitis. Secondarily the route of entry of the foreign bodies is due to an accident, which left behind only a barely visible scar as evidence.

\section{Conclusion}

In cases of unilateral sinusitis and/or sinusitis not responding to any drug regime, possibility of a foreign body in maxillary sinus should be kept in mind. In literature, the most common cause of maxillary sinus foreign body is oroantral fistula. Detailed history focused upon any previous dental procedure or accident should be elicited. And pre-operative CT scan should be ordered. Even though endoscopic approach with wide meatotomy is the most preferred procedure, the surgeon should also be prepared for Caldwell-Luc approach and the need should rise. And efforts should be made to remove all the foreign bodies from the maxillary sinus, irrespective of the impact on the symptom profile of the patient.

\section{References}

[1] Krause, H.R., Rustemeyer, J. and Grunert, R.R. (2002) Foreign Body in Paranasal Sinuses. Mund-, Kiefer- und Gesichtschirurgie, 6, 40-44. http://dx.doi.org/10.1007/s10006-001-0344-5

[2] Liston, P.N. and Walters, R.F. (2002) Foreign Bodies in the Maxillary Antrum: A Case Report. Australian Dental Journal, 47, 344-346. http://dx.doi.org/10.1111/j.1834-7819.2002.tb00549.x

[3] Lima, M.M., Moreira, C.A., da Silva, V.C. and de Freitas, M.R. (2008) 34 Self-Inflicted Foreign Bodies in the Maxil- 
lary Sinus. Revista Brasileira de Otorrinolaringologia, 74, 948.

[4] Mehra, P. and Murad, H. (2004) Maxillary Sinus Disease of Odontogenic Origin. Otolaryngologic Clinics of North America, 37, 347-364. http://dx.doi.org/10.1016/S0030-6665(03)00171-3

[5] Friedlich, J. and Rittenberg, B.N. (2005) Endoscopically Assisted Caldwell-Luc Procedure for Removal of a Foreign Body from the Maxillary Sinus. Journal of the Canadian Dental Association, 71, 200-201.

[6] Costa, F., Robiony, M., Toro, C., Sembronio, S. and Politi, M. (2006) Endoscopically Assisted Procedure for Removal of a Foreign Body from the Maxillary Sinus and Contemporary Endodontic Surgical Treatment of the Tooth. Head Face Medicine, 2, 37. http://dx.doi.org/10.1186/1746-160X-2-37

[7] Chandrasema, F., Singh, A. and Visavadia, B.G. (2010) Removal of a Root from the Maxillary Sinus Using Functional Endoscopic Sinus Surgery. British Journal of Oral and Maxillofacial Surgery, 48, 558-589. http://dx.doi.org/10.1016/j.bjoms.2009.09.007

[8] Hasbini, A.S., Hadi, U. and Ghafari, J. (2001) Endoscopic Removal of an Ectopic Third Molar Obstructing the Osteomeatal Complex. Ear, Nose Throat Journal, 80, 667-670.

[9] Wolf, G., Anderhuber, W. and Kuhn, F. (1993) Development of the Paranasal Sinus in Children. Implications of Paranasal Sinus Surgery. Annals of Otology, Rhinology Laryngology, 102, 705-711.

http://dx.doi.org/10.1177/000348949310200911 
Scientific Research Publishing (SCIRP) is one of the largest Open Access journal publishers. It is currently publishing more than 200 open access, online, peer-reviewed journals covering a wide range of academic disciplines. SCIRP serves the worldwide academic communities and contributes to the progress and application of science with its publication.

Other selected journals from SCIRP are listed as below. Submit your manuscript to us via either submit@scirp.org or Online Submission Portal.
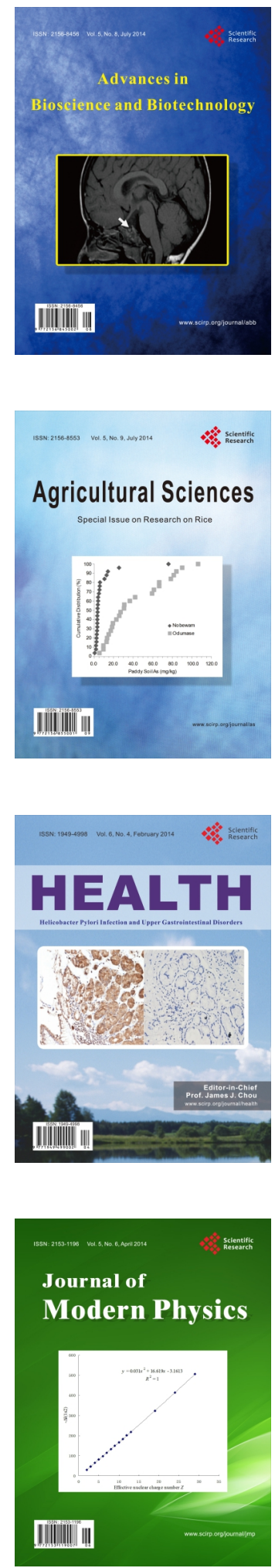
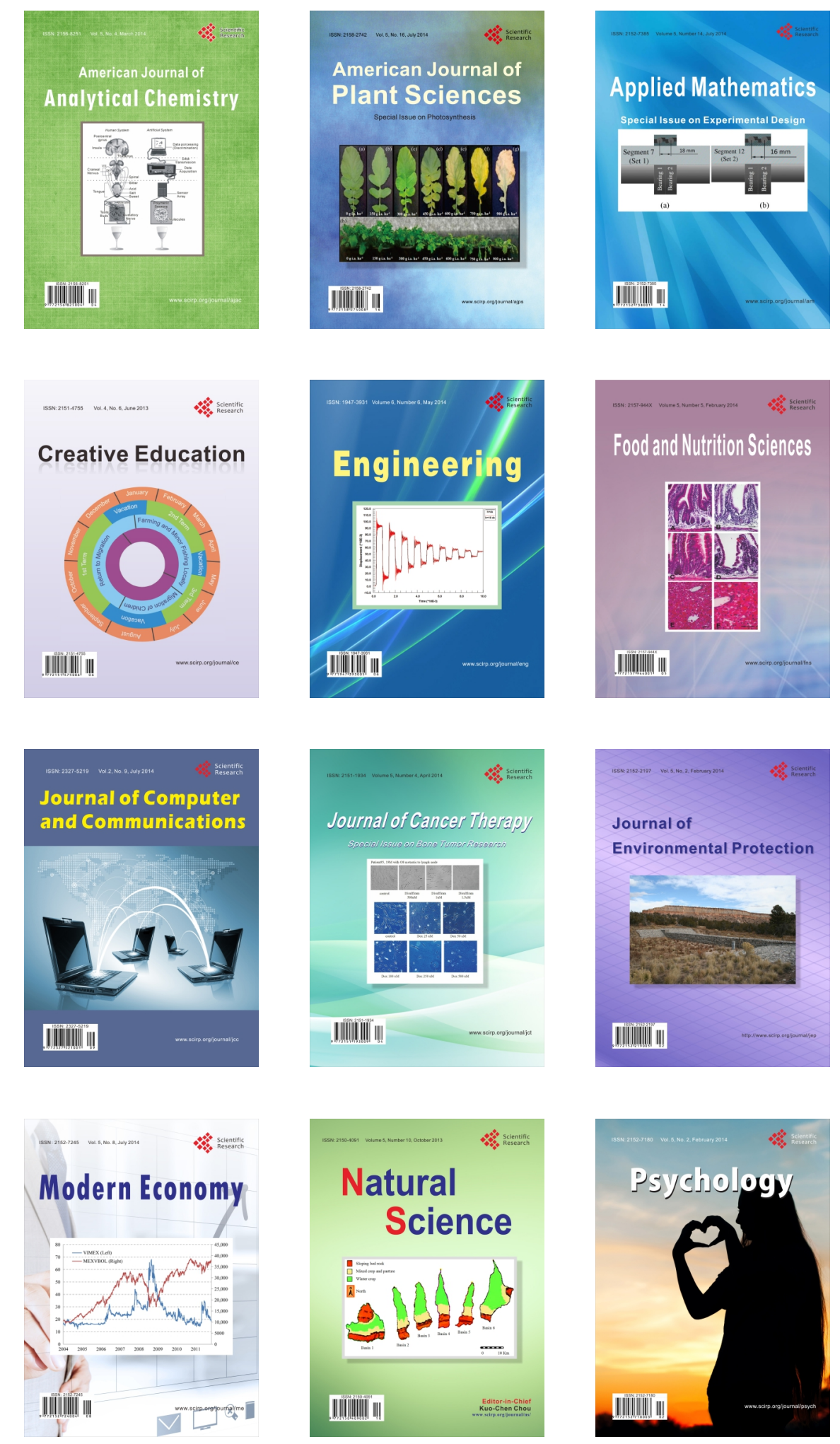